\title{
The Dynamic Effects of Health on the Employment of Older Workers
}

Richard Blundell, Jack Britton, Monica Costa Dias, and Eric French

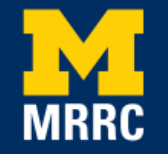

Project \#: UM16-16 


\title{
The Dynamic Effects of Health on the Employment of Older Workers
}

\author{
Richard Blundell
}

Institute for Fiscal Studies

Jack Britton

Institute for Fiscal Studies

Monica Costa Dias

Institute for Fiscal Studies

Eric French

Institute for Fiscal Studies

September 2016

\author{
Michigan Retirement Research Center \\ University of Michigan \\ P.O. Box 1248 \\ Ann Arbor, MI 48104 \\ www.mrrc.isr.umich.edu \\ (734) 615-0422
}

\section{Acknowledgements}

The research reported herein was performed pursuant to a grant from the U.S. Social Security Administration (SSA) funded as part of the Retirement Research Consortium through the University of Michigan Retirement Research Center Award RRC08098401. The opinions and conclusions expressed are solely those of the author(s) and do not represent the opinions or policy of SSA or any agency of the Federal Government. Neither the United States Government nor any agency thereof, nor any of their employees, makes any warranty, express or implied, or assumes any legal liability or responsibility for the accuracy, completeness, or usefulness of the contents of this report. Reference herein to any specific commercial product, process or service by trade name, trademark, manufacturer, or otherwise does not necessarily constitute or imply endorsement, recommendation or favoring by the United States Government or any agency thereof.

\section{Regents of the University of Michigan}

Michael J. Behm, Grand Blanc; Mark J. Bernstein, Ann Arbor; Laurence B. Deitch, Bloomfield Hills; Shauna Ryder Diggs, Grosse Pointe; Denise Ilitch, Bingham Farms; Andrea Fischer Newman, Ann Arbor; Andrew C. Richner, Grosse Pointe Park; Katherine E. White, Ann Arbor; Mark S. Schlissel, ex officio 


\title{
The Dynamic Effects of Health on the Employment of Older Workers
}

\begin{abstract}
Using data from the Health and Retirement Study (HRS) and the English Longitudinal Study of Ageing (ELSA), we estimate a dynamic model of health and employment. We estimate how transitory and persistent health shocks affect employment over time. In a first step, we formulate and estimate a dynamic model of health. The procedure accounts for measurement error and the possibility that people might justify their employment status by reporting bad health. We find that health is well represented by the sum of a transitory white noise process and a persistent AR(1) process. Next, we use the method of simulated moments to estimate the employment response to these shocks. We find that persistent shocks have much bigger effects on employment than transitory shocks, and that these persistent shocks are long lived. For this reason employment is strongly correlated with lagged health, a fact that the usual cross-sectional estimates do not account for. We also show that accounting for the dynamics of health and employment leads to larger estimates of health's effects on employment than what simple OLS estimates of health on employment would imply. We argue that the dynamic effect of health on employment could be generated by a model with human capital accumulation, where negative health shocks slowly reduce the human capital stock, and thus, gradually cause people to exit the labor market.
\end{abstract}

\section{Citation}

Blundell, Richard, Jack Britton, Monica Costa Dias, and Eric French. 2016. "The Dynamic Effects of Health on the Employment of Older Workers.” Ann Arbor, MI. University of Michigan Retirement Research Center (MRRC) Working Paper, WP 2016-348. http://www.mrrc.isr.umich.edu/publications/papers/pdf/wp348.pdf

\section{Authors' acknowledgements}

We thank Richard Johnson and participants at the 2016 RRC conference for helpful comments. 


\section{Introduction}

This paper investigates the dynamic effects of health on the employment of older workers. Specifically, we estimate how transitory and permanent health shocks affect employment over time. Most research on the effect of health on employment does not distinguish between the short and the long run effects and yet these are likely to be very different, and both are important. A transitory health shock, such as a broken bone, may lead some to drop out of work for a short period of time, but many of these workers will be back into employment as their condition improves. However, poor health may have effects on employment that outlive the health condition for a myriad of reasons. For instance, by keeping individuals out of work, poor health may erode the individual competencies that are valued in the labor market, hence reducing productivity. Furthermore, individuals driven off employment because of a bad health shock may have a difficult time returning to the labor force, even if their health improves. The longer poor health conditions persist, the larger the productivity and long-term employment effects are expected to be.

Understanding the dynamic relationship between health and employment is key to informing the effective design and evaluation of public policy. For instance, disability policy aims to protect individuals against risks that are not insurable through the market. In the health context, uninsurable risks are likely related to shocks that persistently impair employment and earnings capacity. In turn, the institutional setting is likely to have a strong influence on the impact of health shocks on employment. Conceivably, more generous health insurance, sickness/incapacity benefits and off-work payments may promote both time off paid work and health investments in response to poor health. These benefits may affect employment in two opposite directions: positively, by leading to a fast recovery and a swift return to work, and negatively, by promoting time out of the labor market in the short run along with the consequent skill depreciation.

The dynamic interactions between health and labor supply are expected to change with age, particularly around retirement age as health problems become increasingly more frequent and serious, and out-of-work benefits change rapidly (Disney et al. (2006), Casanova (2013)). We focus on individuals in the years leading to retirement, aged 50-66, and estimate the overall impact of health on their employment by explicitly taking into account that these effects may build over time. We do this both for England and the US, two countries that share much in terms of culture and values while differing markedly in the institutional context in which older workers frame their decisions, including health policy, working and retirement incentives.

We develop a dynamic model of health and labor supply that allows for rich interactions between the two variables in order to capture the different paths leading to the long-term effects of health. To do so, our model extends those existing in the literature in several directions. ${ }^{1}$ First, we distinguish between transitory and persistent shocks and allow their effects to differ. We believe that separating persistent shocks is crucial for two main reasons: they are a better indicator of the serious health conditions that are likely to limit current working capacity and productivity, and their persistency may lead to magnified consequences inflicted by permanent losses in productivity and labor market attachment. Second, we consider that past health may affect current labor supply, even after conditioning on current health. This may happen because health reduces opportunities for human capital investment, for example. As for current shocks, we allow for the effects of past shocks to differ by the nature of the shock, whether persistent or transitory. Third, we allow for the health effects to be reinforced through additional persistency of the employment

\footnotetext{
${ }^{1}$ E.g. Au et al., 2005, Disney et al. (2006), Bound et al. (1999), Bound et al. (2010), Bound et al. (1999).
} 
process. And fourth, we control for person specific heterogeneity in health, allowing for the possibility that health and labor supply are correlated partly because more motivated people tend to be healthier. Put differently, we relax the assumption that the correlation between health and labor supply is exclusively driven by the effects that health may have on labor supply.

We find that health is well represented by the sum of a transitory white noise process and also a permanent $\mathrm{AR}(1)$ process. Next, we use the method of simulated moments to estimate the employment response to these shocks. We find that permanent shocks have much bigger effects on employment than transitory shocks, and that these permanent shocks are long lived. For this reason, employment is strongly correlated with lagged health, a fact that the usual cross sectional estimates do not account for. We also show that accounting for the dynamics of health and employment leads to larger estimates of the effect of health on employment than what simple OLS estimates of health on employment would imply. We argue that the dynamic effect of health on employment could be generated by a model with human capital accumulation, where negative health shocks slowly reduce the human capital stock, and thus slowly cause people to exit the labor market.

\section{Model}

We consider the health and employment processes of a single cohort, so time is age and is denoted by $a$. All parts of the model are education- and gender-specific, with three education groups: less than High School Dropouts, High School Graduates and University Graduates. In what follows, the gender and education dependencies are omitted to simplify the notation.

The health of individual $i$ at age $a$ follows the process

$$
\begin{aligned}
h_{i a} & =\beta_{0}+x_{i a} \beta_{x}+\pi_{i a}+\epsilon_{i a} \\
\pi_{i a} & =\rho \pi_{i a-1}+\omega_{i a} \\
\omega_{i a}, \epsilon_{i a} & \sim i i d
\end{aligned}
$$

where $h$ is health, $x$ includes an age polynomial and health outcomes of the individual as a child, $\pi_{i a}$ is the persistent health shock, assumed to follow an $\operatorname{AR}(1)$ process with innovation $\omega_{i a}$, and $\epsilon_{i a}$ is a transitory health shock, specified as a white noise. We assume that $\omega_{i a}$ and $\epsilon_{i a}$ are iid. ${ }^{2}$

Our model of employment allows for rich dynamic effects of health on employment. First, we consider that persistent and transitory shocks $(\pi$ and $\epsilon$ ) may have different effects on employment as they may stand for health conditions that limit work and productivity in very different ways. Second, we allow for health shocks to affect current employment, through a direct effect on productivity and preferences, and future employment, through lagged effects on earnings capacity or the ability to move back into work. And third, the persistency of employment may in itself help propagating the impact of health shocks over time. Formally, we specify the dynamic labor supply decision at the extensive margin by the latent variable model:

$$
\begin{aligned}
& E_{i a}^{*}=\alpha_{0}+\alpha_{E 1} E_{i a-1}+\alpha_{E 2}\left(E_{i a-1} * a\right)+x_{i a} \alpha_{x}+\delta_{0} \pi_{i a}+\delta_{1} \pi_{i a-1}+\gamma_{0} \epsilon_{i a}+\gamma_{1} \epsilon_{i a-1}+u_{i a}(4) \\
& E_{i a}=\mathbf{1}\left(E_{i a}^{*}>0\right)
\end{aligned}
$$

\footnotetext{
${ }^{2}$ We considered alternative specifications of unobserved health, including an MA(1) process for the transitory component $\epsilon$ and age-dependent distributions. These did not significantly improve the fit of the health process.
} 
where $E^{*}$ is the latent process for employment and $E$ is the employment indicator. We allow for the effect of lagged employment to vary with age to capture the rapidly changing incentives to work that workers face before retirement. The shock to employment, $u$, is assumed to be iid and independent of the health shocks. We further assume that $(\pi, \epsilon, u)$ are (independently) normally distributed and standardise the variance of $u$ to 1 .

\section{Data}

Our estimates are based on two longitudinal datasets: the US Health and Retirement Study (HRS) and the English Longitudinal Survey of Aging (ELSA). The ELSA data was based upon the design of the US Health and Retirement Study (HRS) data. For this reason, the timing of the interviews, their structure and the information collected are all very similar.

ELSA is designed to be a representative sample of non-institutionalized individuals living in England and aged 50 or older. Interviews were held bi-annually from 2002/03 onwards, with the six currently available waves covering the period up to $2012 / 13$. The sample was drawn from respondents to the Health Survey for England (HSE) in 1998, 1999 or 2001, with refreshment samples added in waves 3 and 6 also drawn from the HSE. Both the selected members of the panel and their partners were interviewed in each wave, resulting in some respondents being younger than 50 at the time of the interview.

HRS began in 1992, with a representative sample of individuals living in the United States aged 50 to 61 . These individuals were interviewed again biennially and refreshment samples were added every 6 years. A self-completion workbook was also left behind for respondents starting in 2004 . Respondents were initially selected from the non-institutionalized population but efforts were made to include them in later waves even if they were admitted into nursing homes. We further augment the HRS dataset with the RAND HRS Data File which contains minor imputations of the core HRS variables and, in general, cleaner data. Similar to ELSA, if an individual is included in the HRS, so too is their partner, regardless of age.

In both cases, our estimates are based on the sub-sample of main respondents and their partners aged 50 to 66 . We use the entire collection of waves for ELSA and the HRS, covering the years up to 2012 .

In total, there are 11,217 individuals in ELSA aged 50-66, of whom $54 \%$ are women. $12 \%$ of our ELSA sample respondents are observed for all 6 waves, and more than half are observed for at least 3 waves. In the HRS there are 24,804 individuals, with the same sex ratio as in ELSA. almost $8 \%$ of the respondents are observed over the 8 waves that cover our age-window, and almost $70 \%$ are observed for at least 3 waves. The education and gender distribution of both samples is detailed in Table 1. We consider three education levels, the lowest corresponding to high-school dropouts in the US and GCSE qualitfications in England, the medium being highschool graduates and the highest level being $3+$ years college degrees. The sample sizes per wave are outlined in Table 3 .

A critical issue for our analysis is how to measure health. The literature on the effects of health has raised concerns that estimates of these impacts may be biased due to measurement error in health. ${ }^{3}$ One problem is that only limited health measures are generally available, and

\footnotetext{
${ }^{3}$ Bound (1991) and Stern (1989).
} 
Table 1: ELSA and HRS sample sizes by education and gender

\begin{tabular}{lccccc}
\hline \hline & \multicolumn{2}{c}{ ELSA } & & \multicolumn{2}{c}{ HRS } \\
\cline { 2 - 3 } \cline { 5 - 6 } & Men & Women & & Men & Women \\
\hline High School dropouts & 1653 & 2362 & & 2437 & 2839 \\
High school & 2312 & 2687 & & 6309 & 8065 \\
College & 1193 & 1010 & & 2635 & 2519 \\
\hline
\end{tabular}

Table 2: ELSA and HRS years and sample sizes

\begin{tabular}{ccccc}
\hline \hline & \multicolumn{2}{c}{ ELSA } & \multicolumn{3}{c}{ HRS } \\
\hline Year & Wave & Sample Size & Wave & Sample Size \\
\hline 1992 & - & - & 1 & 10,857 \\
1994 & - & - & 2 & 9,989 \\
1996 & - & - & 3 & 9,480 \\
1998 & - & - & 4 & 10,311 \\
2000 & - & - & 5 & 8,763 \\
2002 & 1 & 8,008 & 6 & 7,422 \\
2004 & 2 & 6,104 & 7 & 8,733 \\
2006 & 3 & 6,403 & 8 & 7,146 \\
2008 & 4 & 7,426 & 9 & 5,913 \\
2010 & 5 & 6,620 & 10 & 10,544 \\
2012 & 6 & 6,834 & 11 & 9,597 \\
\hline
\end{tabular}

Sample sizes for 50-70 year olds only.

Table 3: ELSA data - observations in selected sample, by wave

\begin{tabular}{ccc}
\hline \hline Wave & Year & Sample Size \\
\hline 1 & 2002 & 6,339 \\
2 & 2004 & 4,781 \\
3 & 2006 & 5,185 \\
4 & 2008 & 5,955 \\
5 & 2010 & 5,139 \\
6 & 2012 & 5,208 \\
\hline
\end{tabular}

those available may capture only one dimension of health. This issue is especially relevant when estimating the effect of objective measures on labour supply. For example, whether an individual has diabetes may or may not have a sizeable effect on labour supply depending, amongst other things, on her other health conditions. Furthermore, people may errantly misreport their health status because they misinterpret a question, or interpret the question differently than others. ${ }^{4}$ Most likely, this type of measurement error leads to an understatement of the effect of health on labour supply. Another problem is that estimates of the effect of health status and labour supply potentially suffer from "justification bias", as those who are not working might claim to be

\footnotetext{
${ }^{4}$ For example Kapteyn et al. (2007) show that differences in reported work disability between the Dutch and Americans largely stem from the fact that Dutch respondents have a lower threshold in reporting whether they have a work disability than American respondents.
} 
unhealthy in order to justify their working status. ${ }^{5}$ This would likely lead to an overstatement of the effect of health on labour supply. In most of these studies, the estimated effect of health on labour supply is found to be larger when using subjective measures than objective measures (Blundell et al. (2016)). These differences in estimates could be attributable to either of these mechanisms.

We deal with measurement error in health by building a composite index using all the objective and subjective self-reported measures of health that are observed in all waves. The objective health measures consist of questions relating to whether the respondent has a given chronic illness (such as cancer or diabetes) and measures on mobility and Activities of Daily Living (ADL). All these are listed in Table 4 , together with some brief descriptive statistics. ${ }^{6}$ Similarly, Table 5 describes all subjective health measures in our index. The two tables clearly demonstrate the similarities in the measurement of health in the two surveys.

We construct the health index using a two step procedure. First, we extract the first factor from a principal component analysis of the set of subjective health measures; this should deal with the first problem mentioned above. Second, we instrument this subjective health factor with objective measures of health, which should take care of justification bias as objective measures are less likely to be sensitive to it. We describe our principal components analysis more carefully in appendix A.

\footnotetext{
${ }^{5}$ See, for example Butler et al. (1987).

${ }^{6}$ The objective health measures are all dichotomous variables about specific conditions, mostly aiming to assess whether the respondent has recently received or is currently receiving treatment for each condition. The subjective health measures aim to assess overall wellbeing and working capacity.
} 
Table 4: Objective health variables

\begin{tabular}{|c|c|c|c|c|c|c|}
\hline Variable & Description & $\overline{\mathrm{N}}$ & Min & Max & Mean & SD \\
\hline \multicolumn{7}{|l|}{ ELSA Data } \\
\hline Cancer & $\begin{array}{l}\text { Received cancer treatment in past } \\
2 \text { years }\end{array}$ & 41361 & 0 & 1 & 0.02 & 0.15 \\
\hline Diabetes & Taking medication for diabetes & 41356 & 0 & 1 & 0.05 & 0.22 \\
\hline Sight & Reported poor eyesight & 41358 & 0 & 1 & 0.02 & 0.14 \\
\hline Hearing & Reported poor hearing & 41360 & 0 & 1 & 0.03 & 0.17 \\
\hline Blood pressure & $\begin{array}{l}\text { Taking medication for high blood } \\
\text { pressure }\end{array}$ & 41389 & 0 & 1 & 0.24 & 0.42 \\
\hline Arthritis & Reported arthritis this wave & 41154 & 0 & 1 & 0.28 & 0.45 \\
\hline Psychiatric & $\begin{array}{l}\text { Reported psychiatric problem this } \\
\text { wave }\end{array}$ & 41391 & 0 & 1 & 0.07 & 0.25 \\
\hline Difficulty Walking One Block & Mobility: Does not (0), does (1) & 41297 & 0 & 1 & 0.09 & 0.28 \\
\hline Difficulty Sitting for Two Hours & Mobility: Does not (0), does (1) & 41297 & 0 & 1 & 0.13 & 0.34 \\
\hline Difficulty Getting Up from a Chair & Mobility: Does not (0), does (1) & 41297 & 0 & 1 & 0.21 & 0.41 \\
\hline $\begin{array}{l}\text { Difficulty Climbing Several Flights of } \\
\text { Stairs }\end{array}$ & Mobility: Does not (0), does (1) & 41297 & 0 & 1 & 0.28 & 0.45 \\
\hline Difficulty Climbing One Flight of Stairs & Mobility: Does not (0), does (1) & 41297 & 0 & 1 & 0.10 & 0.30 \\
\hline $\begin{array}{l}\text { Difficulty Stooping, Kneeling, or Crouch- } \\
\text { ing }\end{array}$ & Mobility: Does not (0), does (1) & 41297 & 0 & 1 & 0.30 & 0.46 \\
\hline Difficulty Lifting or Carrying 10 pounds & Mobility: Does not (0), does (1) & 41297 & 0 & 1 & 0.18 & 0.38 \\
\hline Difficulty Picking Up a Dime & Mobility: Does not (0), does (1) & 41297 & 0 & 1 & 0.04 & 0.20 \\
\hline Difficulty Extending Arms & Mobility: Does not (0), does (1) & 41297 & 0 & 1 & 0.09 & 0.29 \\
\hline Difficulty Pushing or Pulling Large Object & Mobility: Does not (0), does (1) & 41297 & 0 & 1 & 0.13 & 0.34 \\
\hline Difficulty Walking across Room & ADL: Does not $(0)$, does $(1)$ & 41299 & 0 & 1 & 0.02 & 0.15 \\
\hline Difficulty Getting Dressed & ADL: Does not (0), does (1) & 41299 & 0 & 1 & 0.10 & 0.30 \\
\hline Difficulty Bathing or Showering & ADL: Does not $(0)$, does $(1)$ & 41299 & 0 & 1 & 0.07 & 0.26 \\
\hline Difficulty Eating & ADL: Does not (0), does (1) & 41299 & 0 & 1 & 0.02 & 0.12 \\
\hline Difficulty Getting In or Out of Bed & ADL: Does not $(0)$, does $(1)$ & 41299 & 0 & 1 & 0.05 & 0.23 \\
\hline Difficulty Using the Toilet & ADL: Does not (0), does (1) & 41299 & 0 & 1 & 0.03 & 0.16 \\
\hline \multicolumn{7}{|l|}{ HRS Data } \\
\hline Cancer & Reported cancer this wave & 103139 & & 1 & 0.10 & 0.30 \\
\hline Diabetes & Reported diabetes this $\mathrm{w}$ & 103006 & & 1 & 0.18 & 0.38 \\
\hline Sight & Reported poor eyesight & 103253 & 30 & 1 & 0.04 & 0.21 \\
\hline Hearing & Wears hearing aid & 103263 & 30 & 1 & 0.04 & 0.19 \\
\hline Blood pressure & $\begin{array}{l}\text { Reported high blood pressure this } \\
\text { wave }\end{array}$ & 102672 & 20 & 1 & 0.50 & 0.50 \\
\hline Arthritis & Reported arthritis this wave & 102652 & 20 & 1 & 0.52 & 0.50 \\
\hline Psychiatric & $\begin{array}{l}\text { Reported psychiatric problem this } \\
\text { wave }\end{array}$ & 102793 & 30 & 1 & 0.17 & 0.38 \\
\hline Difficulty Walking One Block & Mobility: Does not (0), does (1) & 103052 & 20 & 1 & 0.01 & 0.08 \\
\hline Difficulty Sitting for Two Hours & Mobility: Does not (0), does (1) & 103036 & 60 & 1 & 0.00 & 0.06 \\
\hline Difficulty Getting Up from a Chair & Mobility: Does not (0), does (1) & 103026 & 60 & 1 & 0.00 & 0.05 \\
\hline $\begin{array}{l}\text { Difficulty Climbing Several Flights of } \\
\text { Stairs }\end{array}$ & Mobility: Does not (0), does (1) & 102950 & 0 & 1 & 0.03 & 0.18 \\
\hline Difficulty Climbing One Flight of Stairs & Mobility: Does not (0), does (1) & 103009 & 90 & 1 & 0.02 & 0.13 \\
\hline $\begin{array}{l}\text { Difficulty Stooping, Kneeling, or Crouch- } \\
\text { ing }\end{array}$ & Mobility: Does not (0), does (1) & 103012 & 20 & 1 & 0.02 & 0.15 \\
\hline Difficulty Lifting or Carrying 10 pounds & Mobility: Does not (0), does (1) & 103032 & 20 & 1 & 0.02 & 0.12 \\
\hline Difficulty Picking Up a Dime & Mobility: Does not (0), does (1) & 103039 & 90 & 1 & 0.00 & 0.04 \\
\hline Difficulty Extending Arms & Mobility: Does not (0), does (1) & & 20 & 1 & 0.00 & 0.07 \\
\hline Difficulty Pushing or Pulling Large Object & Mobility: Does not (0), does (1) & 103022 & 20 & 1 & 0.02 & 0.14 \\
\hline Difficulty Walking across Room & ADL: Does not (0), does (1) & 103065 & 50 & 1 & 0.00 & 0.05 \\
\hline Difficulty Getting Dressed & ADL: Does not (0), does (1) & 103073 & 30 & 1 & 0.00 & 0.05 \\
\hline Difficulty Bathing or Showering & ADL: Does not (0), does (1) & 103070 & 0 & 1 & 0.00 & 0.04 \\
\hline Difficulty Eating & ADL: Does not (0), does (1) & 103078 & 80 & 1 & 0.00 & 0.03 \\
\hline Difficulty Getting In or Out of Bed & ADL: Does not (0), does (1) & 103067 & 70 & 1 & 0.00 & 0.03 \\
\hline Difficulty Using the Toilet & ADL: Does not (0), does (1) & 103070 & 0 & 1 & 0.00 & 0.03 \\
\hline
\end{tabular}


Table 5: Subjective health variables

\begin{tabular}{|c|c|c|c|c|c|c|}
\hline Variable & Description & $\mathrm{N}$ & Min & Max & Mean & SD \\
\hline ELSA Data & \multirow{4}{*}{$\begin{array}{l}\text { Does not }(0) \text {, does }(1) \\
\text { Excellent }(1) \text {, very good }(2), \\
\text { good }(3) \text {, fair }(4) \text {, poor }(5) \\
\text { Does not }(0) \text {, does }(1)\end{array}$} & & & & & \\
\hline Health limits activities & & 39421 & 0 & 1 & 0.53 & 0.50 \\
\hline General health & & 36231 & 1 & 5 & 2.59 & 1.11 \\
\hline Health limits work & & 33341 & 0 & 1 & 0.25 & 0.43 \\
\hline \multicolumn{7}{|l|}{ HRS Data } \\
\hline Health limits activities & Does not $(0)$, does $(1)$ & 103273 & 30 & 1 & 0.13 & 0.33 \\
\hline General health & $\begin{array}{l}\text { Excellent (1), very good (2), } \\
\text { good }(3) \text {, fair }(4) \text {, poor }(5)\end{array}$ & 103219 & 91 & 5 & 2.77 & 1.13 \\
\hline Health limits work & Does not $(0)$, does $(1)$ & 99649 & 0 & 1 & 0.26 & 0.44 \\
\hline
\end{tabular}

Our choice to synthesise all health information in a single index is simple and parsimonious, but is only adequate for our purpose of measuring the impact of health on employment if it is capable of summarising the relevant health information for employment. We have investigated this by estimating regression models controlling for more detailed health information and found that adding more detailed information produces results similar to the ones we get with our single index. In particular, we have tried the following. ${ }^{7}$

First, we tried using not just the first principle component but the second principle component of the subjective measures in the employment equation. The regression coefficient on the second principle component was not statistically significant and was small in magnitude. This holds whether or not we just regressed employment on the first and second principle components or instrumented for these two principle components using the objective health measures. Thus we decided that little would be gained by adding the second principle component.

Second, we tried regressing employment on all the objective health measures. This procedure produced similar but less stable and usually smaller estimated effects of health on employment than our preferred method of regressing employment on our single health index. ${ }^{8}$ We attribute our more stable and slightly larger estimates using our procedure to the fact that our procedure handles measurement error in the objective health measures. See also Blundell et al. (2016) for more details on the data, and the robustness of estimates to alternative measures of health.

\section{Estimation}

For simplicity, we denote by 0 the youngest age group in our sample, aged 50-51. The parameters of interest are those characterising the dynamics of health, $\left(\rho, \sigma_{\omega}, \sigma_{\pi_{0}}, \sigma_{\epsilon}\right)$, its effect on employment $\left(\eta_{0}, \eta-1, \delta_{0}, \delta_{1}, \gamma\right)$, the effects of lagged employment on current employment $\left(\alpha_{E 1}, \alpha_{E 2}\right)$, and the initial (at age 0 ) correlation between employment and the health error components $\left(\sigma_{E_{0} \pi_{0}}, \sigma_{E_{0} \epsilon_{0}}\right)$.

We estimate the model in two steps. First, the parameters in the health process $\left(\rho, \sigma_{\omega}, \sigma_{\pi_{0}}, \sigma_{\epsilon}\right)$ can be estimated in a first stage by using an error components model. We estimate the parameter

\footnotetext{
${ }^{7}$ Detailed results available from the authors upon request.

${ }^{8}$ For example, we calculated the share of the employment decline between ages 52 and 69 that can be explained by declining health as implied by our health index or by the entire set of objective measures. Using our our preferred approach and averaging over our education groups, we can explain $12 \%$ of the decline in employment among men in both the ELSA and HRS data. The similar measures using the collection of objective measures is $5 \%$ and $12 \%$ for the ELSA and HRS data, respectively.
} 
vector that best matches the empirical auto-covariance matrix of health residuals, where the health residuals are constructed using a regression of health on an age polynomial only. The time correlations in individual residuals separate the structure of the persistent and transitory health shocks. Since health is pre-determined in our model, the parameters of the health model can be estimated without any reference to the employment decision.

In the second step we estimate the other model parameters using the Method of Simulated Moments conditional on the structure of the health process. ${ }^{9}$ The estimation procedure at this stage is conditional on the parameters driving the health shocks. We assume all health and employment residuals are normally distributed and independent, so the employment regression is a probit. Lagged employment is endogenous in this regression given its relationship with health residuals. We explicitly account for this dependence by simulating employment conditional on health shocks, using simulated lagged employment in predicting future employment status, and by matching employment rates by age and the autocovariances of employment calculated on this simulated series with their data counterparts. Furthermore, endogeneity of initial employment is dealt with by starting the simulations 4 periods ( 8 years) prior to the start of the age interval observed in the data.

For any set of parameters, $\left(\delta_{0}, \delta_{1}, \gamma_{0}, \gamma_{1}, \alpha_{E 1}, \alpha_{E 2}\right)$, we simulate the health residuals and the employment process over the entire observation period for every individual and select the parameter vector that minimizes the GMM criterion:

$$
\left(\hat{M}^{d}-M^{m}(\Theta)\right)^{\prime} \hat{\Omega}^{-1}\left(\hat{M}^{d}-M^{m}(\Theta)\right)
$$

where $\left(\hat{M}^{d}, M^{m}\right)$ are the data and model simulated moments, respectively, and $\hat{\Omega}$ is the estimated variance-covariance matrix of the data moments estimates. We then select the set of parameters for which the moments calculated from the simulated data best match moments estimated with ELSA or HRS data. We chose to match 3 sets of moments: the auto-covariance matrix of employment, the matrix of cross-correlations between employment and health residuals, and a set of moments describing employment probabilities by age. Since the dynamic structure of the health process is known at this stage, the cross-correlations between employment and health help identifying the coefficients driving the effects of health on employment (the $\delta$ 's and $\gamma$ 's). Then the other moments capture the employment rates, how they change with age and the coefficients on lagged employment. ${ }^{10}$

The following describes our procedure to estimate $\Theta=\left(\delta_{0}, \delta_{1}, \gamma_{0}, \gamma_{1}, \alpha_{E 1}, \alpha_{E 2}\right)$ conditional on the parameters characterising the residual health process and estimated in step $1,\left(\hat{\rho}, \hat{\sigma}_{\omega}, \hat{\sigma}_{\pi_{0}}, \hat{\sigma}_{\epsilon}\right)$.

1. Estimate all moments and the variance-covariance matrix of these estimates on survey data (ELSA or HRS) for 50-65 year olds.

2. Using the estimated parameters from step 1, simulate the health residuals process from the age of 42 to 65 .

3. Choose initial values of the parameters being estimated in the second stage and get employment at age 42 from historical data.

4. Simulate the employment process from age 42 to 65 .

\footnotetext{
${ }^{9}$ Original references are McFadden (1989) and Pakes and Pollard (1989).

${ }^{10}$ Further details of our identification strategy can be found in the appendix B.
} 
5. Calculate the model generated moments using simulations for the age group 50-65.

6. Compare model generated moments to the moments in the data. Calculate the GMM criterion.

7. Take a new set of parameters (where the new set is taken using a Nelder-Mead/Amoeba algorithm) and repeat steps 4-6 until a global minimum is found.

\section{Results}

Our key findings are as follows:

1. The dynamic properties of health are well described by the sum of a highly persistent $\operatorname{AR}(1)$ component, plus a transitory component.

2. Transitory health shocks have little impact on employment.

3. Permanent health shocks have much bigger effects on employment.

4. Employment is highly persistent. Lagged employment strongly predicts current employment, even after accounting for the persistence in health.

5. Model estimates suggest a larger impact of health on employment than what OLS estimates imply.

This section describes these findings in greater depth.

\subsection{The health process}

\subsubsection{Estimates}

Table 6 presents estimates of the parameters of the health process using ELSA and HRS data. Estimates are by gender for the three educational groups we consider, corresponding to high-school dropouts (Ed 1), high-school graduates (Ed 2) and college graduates (Ed 3).

The figures in Table 6 show show remarkable similarities between the health processes estimated for the two countries. In both cases, the dynamic properties of health are well described by the sum of a highly persistent $\mathrm{AR}(1)$ component plus a transitory component. Moreover, the autocorrelation parameter $(\rho)$ is close to 0.9 for all groups. However, the dispersions in the initial permanent health component $\left(\sigma_{\pi 0}\right)$ and in persistent health shocks $\left(\sigma_{\omega}\right)$ are generally higher in England than in the US. These differences are partly compensated amongst low and medium educated men, who face an higher dispersion in the transitory health shocks $(\epsilon)$ in the US than in England. More generally, the variability of both the transitory and the permanent health shocks vary a great deal from group to group. 


\begin{tabular}{lcccc}
\hline \hline & \multicolumn{4}{c}{ Health parameters } \\
\cline { 2 - 5 } & $\begin{array}{c}\text { Var pers. shock } \\
\left(\sigma_{\omega}^{2}\right)\end{array}$ & $\begin{array}{c}\text { Var initial } \begin{array}{c}\text { Autocorr coeff } \\
\left(\sigma_{\pi 0}^{2}\right)\end{array} \\
(\rho)\end{array}$ & $\begin{array}{c}\text { Var trans. shock } \\
\left(\sigma_{\epsilon}^{2}\right)\end{array}$ \\
\hline \hline & \multicolumn{4}{c}{ Estimates for England } \\
Men, Ed 1 & 0.325 & 0.988 & 0.903 & 0.047 \\
Men, Ed 2 & 0.171 & 1.045 & 0.914 & 0.123 \\
Men, Ed 3 & 0.100 & 0.705 & 0.920 & 0.166 \\
Women, Ed 1 & 0.137 & 0.622 & 0.934 & 0.108 \\
Women, Ed 2 & 0.024 & 0.121 & 1.058 & 0.120 \\
Women, Ed 3 & 0.059 & 0.475 & 0.984 & 0.118 \\
\hline & & & & \\
Men, Ed 1 & & Estimates for the US & 0.254 \\
Men, Ed 2 & 0.097 & 0.604 & 0.893 & 0.219 \\
Men, Ed 3 & 0.051 & 0.679 & 0.951 & 0.133 \\
Women, Ed 1 & 0.073 & 0.368 & 0.907 & 0.133 \\
Women, Ed 2 & 0.051 & 0.395 & 0.940 & 0.070 \\
Women, Ed 3 & 0.020 & 0.159 & 0.956 & 0.041 \\
\hline \hline
\end{tabular}

Table 6: Parameter estimates for the health process 50-66 (diagonal weights). Ed 1, 2, 3 is high-school dropouts, high school graduates and college graduates respectively.

\subsubsection{Model Fit}

Figures 1 and 2 show how the model fits the variance of health across the different age groups. Unsurprisingly, those with the lowest education have the most variable health for both genders, and for both England and the US. Moreover, the health measure is more disperse among men than it is among women. This is consistent with low educated men being especially at risk of serious negative health shocks and with the high disability rates among them.

The results for England show, as expected, that the variability of health rises with age as some people remain healthy while others accumulate health problems or are hit by large negative health shocks. However, this pattern is not clear in the US, where indeed the variability of the health process is mostly flat or even mildly decreasing with age among low and medium educated men. Moreover, in line with estimates in Table 6, these figures show that the dispersion of health in England is higher than that in the US for all groups at all ages. In future work, we will investigate the connections between our health indexes and the specific health conditions underlying them to shed light on these cross-country differences in levels and age patterns. 


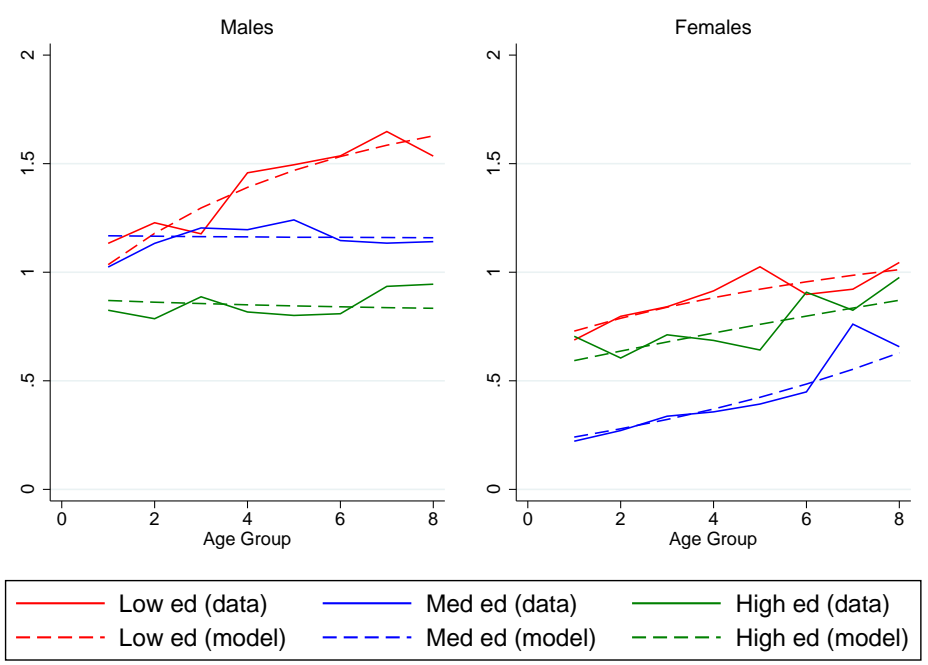

Figure 1: England - model fit for the variance of health on age, by gender and education. Low, Med and High Ed stad for high-school dropouts, high school graduates and college graduates respectively.

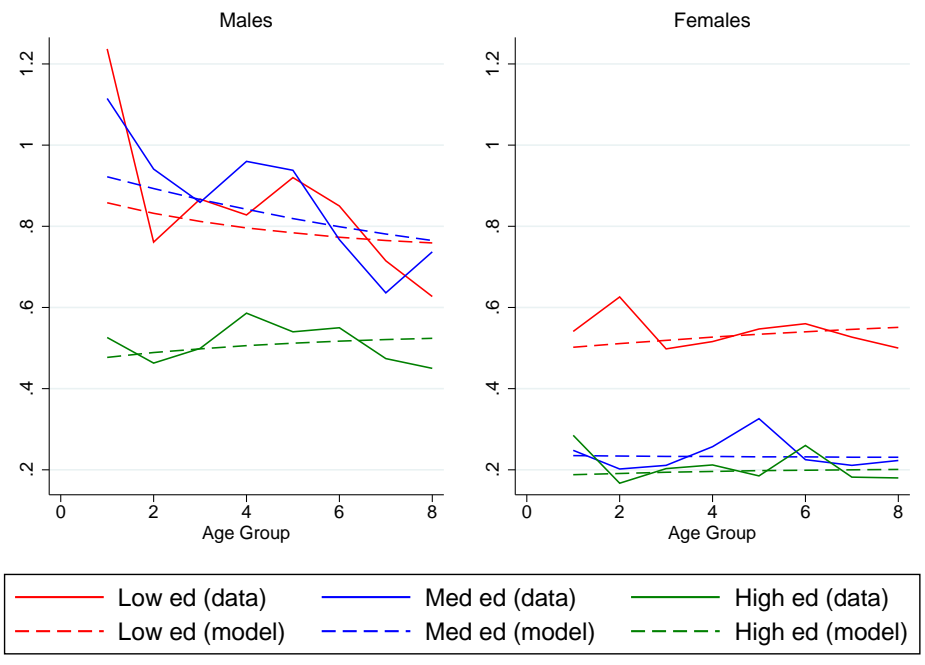

Figure 2: US - model fit for the variance of health on age, by gender and education. Low, Med and High Ed stad for high-school dropouts, high school graduates and college graduates respectively.

Figures 1 and 2 show that the model captures well the age patterns in the variance of health. These variances are a subset of the moments we use in estimation, corresponding to the diagonal elements of the auto-covariance matrix of the health residuals. The fit of the remaining moments are shown in Tables 7 and 8 for high-school dropout men. Similar figures are available from the authors for the other groups.

Tables 7 and 8 show that the model also captures the covariances well. For both datasets, there is a big drop between the variance and first autocovariance. For example, the variance of 
the health index for 50-51 years old in England is 1.133, but the first auto-covariance (between age 50-51 and 52-53) is 0.878. A similar pattern can be seen for all other groups. This drop is consistent with the view that there is a non-trivial transitory component to health. Subsequent covariances remain high, however. For example, the covariance between health at age 50-51 and 60-61 is 0.623 , which is consistent with the view that there is an important persistent component of health. As we show below, the employment responses to the transitory and persistent components of health are very different.

\begin{tabular}{lcccccccc}
\hline \hline & \multicolumn{7}{c}{ Age groups } \\
\cline { 2 - 9 } Age groups & $50-51$ & $52-53$ & $54-55$ & $56-57$ & $58-59$ & $60-61$ & $62-63$ & $64-65$ \\
\hline \hline & & \multicolumn{7}{c}{ Data } \\
$50-51$ & 1.133 & & \multicolumn{6}{c}{} \\
$52-53$ & 0.878 & 1.228 & & & & & & \\
$54-55$ & 0.857 & 0.964 & 1.177 & & & & & \\
$56-57$ & 0.803 & 0.946 & 1.071 & 1.458 & & & & \\
$58-59$ & 0.731 & 0.774 & 1.076 & 1.321 & 1.495 & & & \\
$60-61$ & 0.623 & 0.783 & 0.777 & 1.195 & 1.198 & 1.536 & & \\
$62-63$ & & 0.641 & 0.682 & 0.983 & 1.241 & 1.330 & 1.648 & \\
$64-65$ & & & 0.633 & 0.953 & 1.254 & 1.229 & 1.374 & 1.535 \\
\hline & & & & & & & & \\
$50-51$ & 1.035 & & & & & & & \\
$52-53$ & 0.893 & 1.179 & & & & & & \\
$54-55$ & 0.806 & 1.022 & 1.296 & & & & & \\
$56-57$ & 0.728 & 0.923 & 1.128 & 1.391 & & & & \\
$58-59$ & 0.658 & 0.834 & 1.019 & 1.214 & 1.469 & & & \\
$60-61$ & 0.595 & 0.754 & 0.921 & 1.097 & 1.285 & 1.533 & & \\
$62-63$ & & 0.681 & 0.832 & 0.991 & 1.161 & 1.342 & 1.585 & \\
$64-65$ & & & 0.751 & 0.895 & 1.049 & 1.213 & 1.389 & 1.628 \\
\hline \hline
\end{tabular}

Table 7: England - Health variance covariance matrix for men, high-school dropouts, data vs model 


\begin{tabular}{lcccccccc}
\hline \hline & \multicolumn{7}{c}{ Age groups } \\
\cline { 2 - 9 } Age groups & $50-51$ & $52-53$ & $54-55$ & $56-57$ & $58-59$ & $60-61$ & $62-63$ & $64-65$ \\
\hline \hline & & \multicolumn{7}{c}{ Data } \\
$50-51$ & 1.237 & & \multicolumn{7}{c}{} & & & \\
$52-53$ & 0.424 & 0.761 & & & & & & \\
$54-55$ & 0.528 & 0.422 & 0.867 & & & & & \\
$56-57$ & 0.569 & 0.436 & 0.538 & 0.828 & & & & \\
$58-59$ & 0.514 & 0.382 & 0.462 & 0.467 & 0.920 & & & \\
$60-61$ & 0.477 & 0.345 & 0.409 & 0.451 & 0.505 & 0.850 & & \\
$62-63$ & 0.243 & 0.321 & 0.354 & 0.419 & 0.456 & 0.483 & 0.715 & \\
$64-65$ & 0.197 & 0.341 & 0.277 & 0.286 & 0.410 & 0.391 & 0.470 & 0.627 \\
\hline & & & & & & & & \\
$50-51$ & 0.858 & & & & & & & \\
$52-53$ & 0.539 & 0.832 & & & & & & \\
$54-55$ & 0.481 & 0.516 & 0.812 & & & & & \\
$56-57$ & 0.429 & 0.461 & 0.498 & 0.796 & & & & \\
$58-59$ & 0.383 & 0.412 & 0.445 & 0.484 & 0.784 & & & \\
$60-61$ & 0.342 & 0.367 & 0.397 & 0.432 & 0.473 & 0.773 & & \\
$62-63$ & 0.306 & 0.328 & 0.355 & 0.386 & 0.422 & 0.464 & 0.765 & \\
$64-65$ & 0.273 & 0.293 & 0.317 & 0.345 & 0.377 & 0.414 & 0.457 & 0.759 \\
\hline \hline
\end{tabular}

Table 8: US - Health variance covariance matrix for men, high-school dropouts, data vs model

\subsection{The employment process}

\subsubsection{Estimates}

The coefficient estimates for the employment process are given in Table 9 . The coefficients $\alpha_{E 1}$ and $\alpha_{E 2}$ suggest a high degree of persistence in employment. For instance, estimates imply that the index $E^{*}$ raises by 1.256 for a 50 year old, high-school dropout man in England if they worked in the previous period, and it raises by $1.256+5^{*} 0.419=3.351$ at the age of 60 . To put these values in perspective, take the values of $\left(\operatorname{var}\left(\pi_{0}\right), \operatorname{var}(\epsilon)\right)$ to be $(1,0.05)$, similar to the figures in Table 6 , and the value of all other coefficients in the employment index (except the effect of lagged employment) to be zero. Then the predicted probability of employment at age 50 would be .5 if not working in the previous period and .79 if working the previous period. ${ }^{11}$ Lagged employment is also a main driver of current employment in the US, with estimates very close to those obtained for England.

The estimates of the impact of persistent shocks are very similar in both countries, generally larger for men than for women and decreasing in education attainment (coefficients on $\pi$ and its lag). The effects of the transitory shocks show no clear patterns, varying widely by education, gender and country, which suggests they are not important drivers of employment.

\footnotetext{
${ }^{11}$ The variance of the residual in the equation is $1+1 * 0.687-0.05^{*} 2.649=1.55$. So $\Phi(0)=.5$ if not working in the previous period and $\Phi(1.256 / 1.55)=.79$ if working the previous period.
} 


\begin{tabular}{|c|c|c|c|c|c|c|c|c|}
\hline & \multicolumn{8}{|c|}{ Coefficients in employment process } \\
\hline & $\begin{array}{c}\text { constant } \\
\left(\alpha_{0}\right) \\
\end{array}$ & $\begin{array}{l}E_{t-1} \\
\left(\alpha_{E 1}\right) \\
\end{array}$ & $\begin{array}{c}E_{t-1} \times \text { age } \\
\left(\alpha_{E 2}\right)\end{array}$ & $\begin{array}{l}\text { age } \\
\left(\alpha_{2}\right)\end{array}$ & $\begin{array}{l}\text { age }^{2} \\
\left(\alpha_{3}\right)\end{array}$ & $\begin{array}{l}\text { age }^{3} \\
\left(\alpha_{4}\right) \\
\end{array}$ & $\begin{array}{c}\text { coeffs on }\left(\pi_{t}, \pi_{t-1}\right) \\
\left(\sum \delta\right)\end{array}$ & $\begin{array}{c}\text { coeffs on }\left(\epsilon_{t}, \epsilon_{t-1}\right) \\
\left(\sum \gamma\right)\end{array}$ \\
\hline & \multicolumn{8}{|c|}{ Estimates for England } \\
\hline Men, Ed 1 & 0.025 & 1.256 & 0.419 & -.249 & 0.022 & -.008 & 0.687 & -2.649 \\
\hline Men, Ed 2 & -1.155 & 2.951 & 0.042 & -.167 & 0.052 & -.008 & 0.465 & -1.424 \\
\hline Men, Ed 3 & -.279 & 2.258 & 0.413 & -.274 & -.023 & -.002 & 0.463 & -.397 \\
\hline Women, Ed 1 & -.436 & 1.998 & 0.090 & -.003 & -.066 & 0.005 & 0.271 & 0.532 \\
\hline Women, Ed 2 & -.036 & 1.786 & 0.027 & 0.333 & -.197 & 0.017 & 0.389 & -.517 \\
\hline \multirow[t]{2}{*}{ Women, Ed 3} & -.357 & 2.362 & 0.046 & 0.120 & -.102 & 0.007 & 0.205 & 0.158 \\
\hline & \multicolumn{8}{|c|}{ Estimates for the US } \\
\hline Men, Ed 1 & -1.140 & 3.023 & -.043 & 0.244 & -.062 & 0.001 & 1.113 & -1.970 \\
\hline Men, Ed 2 & -1.528 & 2.696 & -.061 & 0.153 & 0.034 & -.007 & 0.354 & -.207 \\
\hline Men, Ed 3 & -.653 & 2.444 & 0.052 & 0.000 & -.018 & -.001 & 0.501 & -.568 \\
\hline Women, Ed 1 & -1.582 & 2.264 & 0.042 & 0.099 & 0.018 & -.005 & 0.410 & -1.245 \\
\hline Women, Ed 2 & 0.292 & 0.456 & 0.168 & 0.077 & -.073 & 0.005 & 0.374 & 0.013 \\
\hline Women, Ed 3 & -1.049 & 2.983 & -.059 & -.021 & -.004 & -.001 & 0.161 & -.197 \\
\hline
\end{tabular}

Table 9: Estimates of parameters in dynamic employment process. Ed 1, 2, 3 stand for high-school dropouts, high school graduates and college graduates respectively. Parameters correspond to coefficients in equation 10, where $\alpha_{2}, \alpha_{3}, \alpha_{4}$ are the coefficients on the age cubic.

\subsubsection{Model Fit}

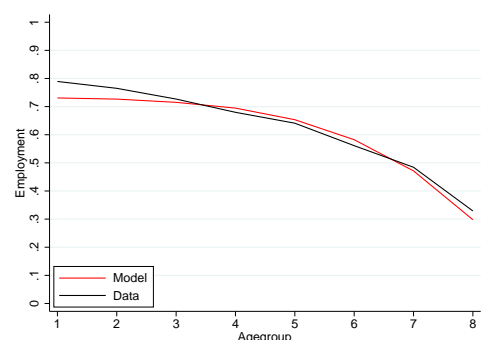

Men, high-school dropouts

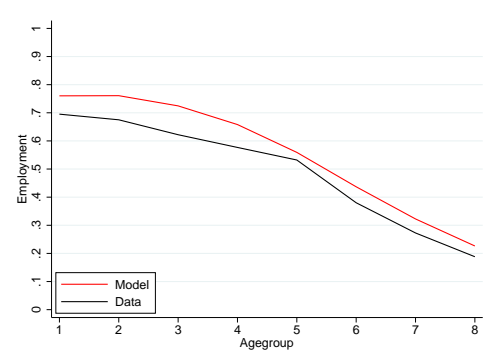

Women, high-school dropouts

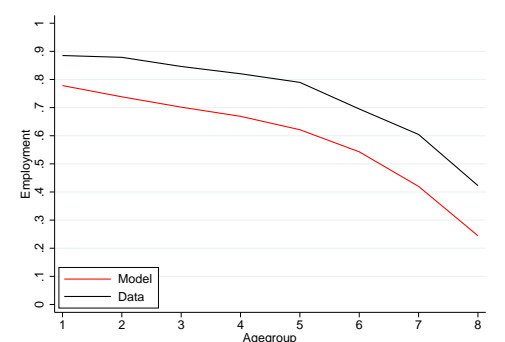

Men, high-school graduates

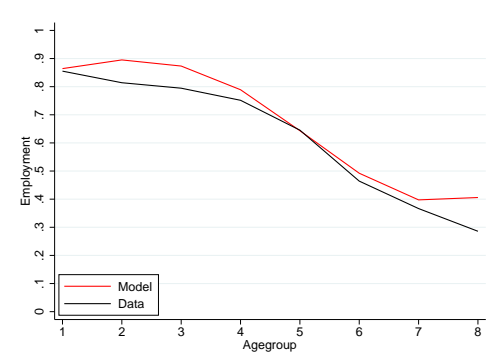

Women, high-school graduates

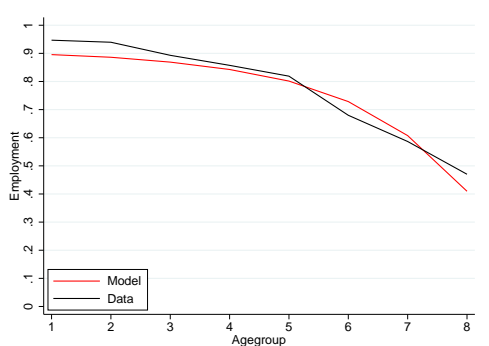

Men, college dropouts

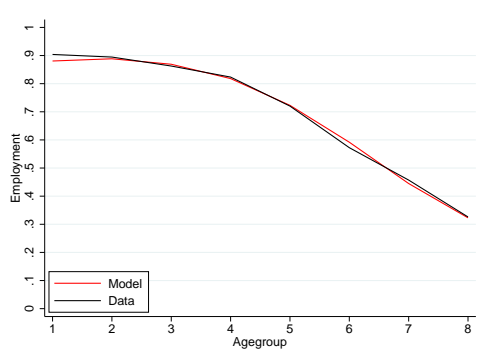

Women, college graduates

Figure 3: England - Mean employment, actual (black) vs model (red) by gender and education. 


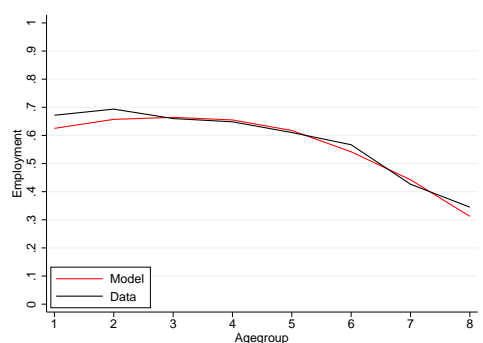

Men, high-school dropouts

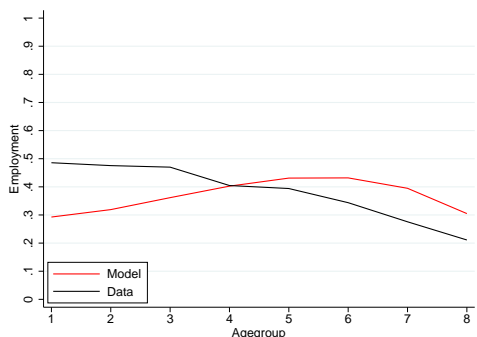

Women, high-school dropouts

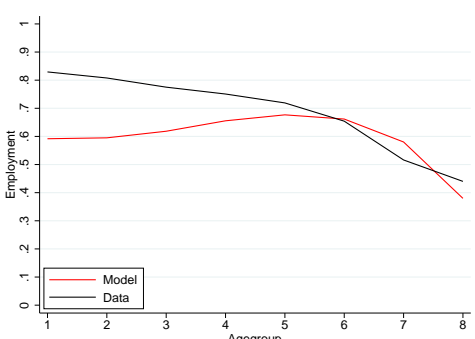

Men, high-school graduates

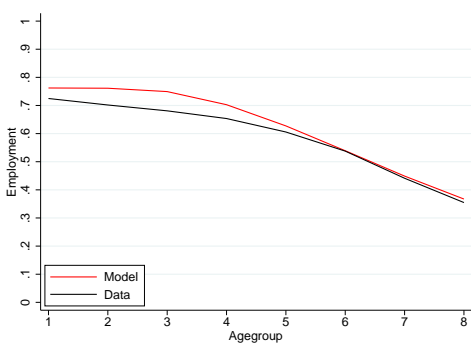

Women, high-school graduates

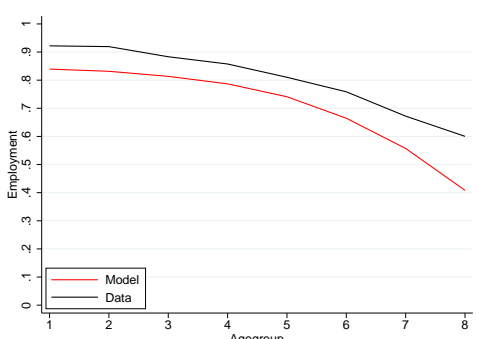

Men, college dropouts

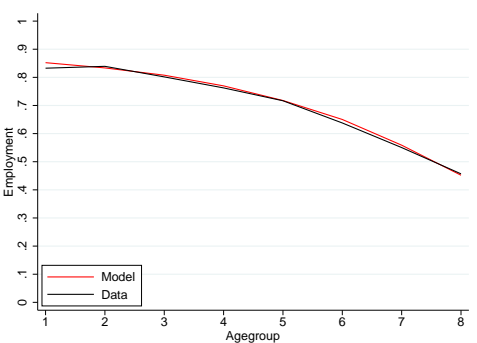

Women, college graduates

Figure 4: US - Mean employment, actual (black) vs model (red) by gender and education.

Figures 4 and 3 contrast survey employment profiles by age with those predicted by the model. The fit is generally good but not equally so for all groups. For England, the model does worse in capturing the employment level of high-school graduated men, while for the US it fails to capture the employment profile of high-school graduated men and high-school dropout women, as well as the employment level of college graduated men.

Other moments are closely fit. Tables 10 and 11 show the variance-covariance matrix of employment for high-school dropout men estimated on survey data and predicted by the model, for England and the US respectively. ${ }^{12}$ Employment is highly serially correlated. This serial correlation in employment is captured both through the lagged employment parameter and through the persistent component of health.

\footnotetext{
${ }^{12}$ Similar figures for other groups available from the authors.
} 


\begin{tabular}{lcccccccc}
\hline \hline & \multicolumn{7}{c}{ Age groups } \\
\cline { 2 - 9 } Age groups & $50-51$ & $52-53$ & $54-55$ & $56-57$ & $58-59$ & $60-61$ & $62-63$ & $64-65$ \\
\hline \hline & & \multicolumn{7}{c}{ Data } \\
$50-51$ & 0.1672 & & & & & & \\
$52-53$ & 0.1344 & 0.1803 & & & & & & \\
$54-55$ & 0.1203 & 0.1491 & 0.1990 & & & & & \\
$56-57$ & 0.1057 & 0.1452 & 0.1542 & 0.2181 & & & & \\
$58-59$ & 0.0687 & 0.1146 & 0.1364 & 0.1699 & 0.2305 & & & \\
$60-61$ & 0.0092 & 0.0884 & 0.1245 & 0.1522 & 0.1639 & 0.2466 & & \\
$62-63$ & & 0.0538 & 0.1101 & 0.1269 & 0.1466 & 0.1822 & 0.2501 & \\
$64-65$ & & & 0.0943 & 0.0850 & 0.1041 & 0.1143 & 0.1425 & 0.2211 \\
\hline & & & & & & & & \\
$50-51$ & 0.1967 & & & & & & & \\
$52-53$ & 0.1322 & 0.1986 & & & & & & \\
$54-55$ & 0.1001 & 0.1490 & 0.2037 & & & & & \\
$56-57$ & 0.0840 & 0.1212 & 0.1644 & 0.2121 & & & & \\
$58-59$ & 0.0758 & 0.1064 & 0.1424 & 0.1834 & 0.2265 & & & \\
$60-61$ & 0.0671 & 0.0914 & 0.1224 & 0.1569 & 0.1947 & 0.2432 & & \\
$62-63$ & & 0.0738 & 0.0987 & 0.1263 & 0.1564 & 0.1952 & 0.2492 & \\
$64-65$ & & & 0.0638 & 0.0814 & 0.0990 & 0.1232 & 0.1572 & 0.2092 \\
\hline \hline
\end{tabular}

Table 10: England - Employment variance covariance matrix for men, high-school dropouts, data vs model

\begin{tabular}{lcccccccc}
\hline \hline & \multicolumn{7}{c}{ Age groups } \\
\cline { 2 - 9 } Age groups & $50-51$ & $52-53$ & $54-55$ & $56-57$ & $58-59$ & $60-61$ & $62-63$ & $64-65$ \\
\hline \hline & & \multicolumn{7}{c}{ Data } \\
$50-51$ & 0.2212 & & & & & & \\
$52-53$ & 0.1532 & 0.2128 & & & & & & \\
$54-55$ & 0.1251 & 0.1548 & 0.2246 & & & & & \\
$56-57$ & 0.1332 & 0.1315 & 0.1637 & 0.2281 & & & & \\
$58-59$ & 0.1323 & 0.1188 & 0.1491 & 0.1703 & 0.2380 & & & \\
$60-61$ & 0.0726 & 0.0922 & 0.1154 & 0.1377 & 0.1655 & 0.2457 & & \\
$62-63$ & 0.0672 & 0.0705 & 0.0910 & 0.0997 & 0.1181 & 0.1536 & 0.2448 & \\
$64-65$ & 0.0457 & 0.0682 & 0.0847 & 0.0818 & 0.0865 & 0.1145 & 0.1539 & 0.2262 \\
\hline & & & & & & & & \\
$50-51$ & 0.2344 & & & & & & & \\
$52-53$ & 0.1776 & 0.2254 & & & & & & \\
$54-55$ & 0.1376 & 0.1737 & 0.2230 & & & & & \\
$56-57$ & 0.1081 & 0.1334 & 0.1713 & 0.2260 & & & & \\
$58-59$ & 0.0907 & 0.1091 & 0.1355 & 0.1779 & 0.2362 & & & \\
$60-61$ & 0.0733 & 0.0864 & 0.1053 & 0.1344 & 0.1783 & 0.2483 & & \\
$62-63$ & 0.0567 & 0.0663 & 0.0804 & 0.1007 & 0.1302 & 0.1792 & 0.2467 & \\
$64-65$ & 0.0410 & 0.0471 & 0.0557 & 0.0677 & 0.0857 & 0.1146 & 0.1581 & 0.2148 \\
\hline
\end{tabular}

Table 11: England - Employment variance covariance matrix for men, high-school dropouts, data vs model

Tables 12 and 13 show the covariance matrix of health and employment for men who are highschool dropouts in England and the US, respectively. ${ }^{13}$ Interestingly, employment correlation with lagged health is similar the employment correlation with current health. For example,

\footnotetext{
${ }^{13}$ Again, similar moments for the other education and gender groups can be obtained from the authors.
} 
in England the covariance between employment and health at ages 58-59 is 0.3384 , whereas covariance between employment at ages 58-59 and health at ages 56-57 is 0.3427.

Lagged health is likely to be highly correlated with employment through two channels within the model. First, health itself is persistent. Second, health impacts employment, which in turn affects future employment. To get a better sense of the importance of these mechanisms, we simulate the impact of health shocks on employment below.

\begin{tabular}{lcccccccc}
\hline \hline \multirow{2}{*}{$\begin{array}{l}\text { Health by } \\
\text { age groups }\end{array}$} & \multicolumn{7}{c}{ Employment by age group } \\
\cline { 2 - 9 } & $50-51$ & $52-53$ & $54-55$ & $56-57$ & $58-59$ & $60-61$ & $62-63$ & $64-65$ \\
\hline \hline $50-51$ & 0.2813 & 0.2640 & 0.2368 & 0.2029 & 0.1716 & 0.1253 & & \\
$52-53$ & 0.2828 & 0.2758 & 0.2854 & 0.2996 & 0.2569 & 0.1771 & 0.1789 & \\
$54-55$ & 0.2702 & 0.2717 & 0.2991 & 0.3014 & 0.3212 & 0.2035 & 0.2504 & 0.2278 \\
$56-57$ & 0.2566 & 0.2769 & 0.3048 & 0.3111 & 0.3427 & 0.2854 & 0.2828 & 0.2807 \\
$58-59$ & 0.2239 & 0.1934 & 0.2795 & 0.3426 & 0.3384 & 0.2983 & 0.3131 & 0.3121 \\
$60-61$ & 0.1357 & 0.1749 & 0.1894 & 0.2892 & 0.2762 & 0.3186 & 0.3169 & 0.2751 \\
$62-63$ & & 0.1302 & 0.1897 & 0.2476 & 0.2554 & 0.3093 & 0.3231 & 0.2748 \\
$64-65$ & & & 0.1636 & 0.1844 & 0.1955 & 0.2221 & 0.2045 & 0.1884 \\
\hline & & & & & & & & \\
$50-51$ & 0.2131 & 0.1935 & 0.1888 & 0.1850 & 0.1835 & 0.1784 & & \\
$52-53$ & 0.2034 & 0.2362 & 0.2295 & 0.2284 & 0.2283 & 0.2225 & 0.2086 & \\
$54-55$ & 0.1823 & 0.2233 & 0.2593 & 0.2579 & 0.2632 & 0.2626 & 0.2473 & 0.1882 \\
$56-57$ & 0.1655 & 0.2007 & 0.2424 & 0.2809 & 0.2887 & 0.2926 & 0.2801 & 0.2161 \\
$58-59$ & 0.1476 & 0.1813 & 0.2191 & 0.2616 & 0.3037 & 0.3113 & 0.3051 & 0.2365 \\
$60-61$ & 0.1323 & 0.1623 & 0.1948 & 0.2347 & 0.2816 & 0.3267 & 0.3219 & 0.2609 \\
$62-63$ & & 0.1470 & 0.1756 & 0.2123 & 0.2553 & 0.3028 & 0.3397 & 0.2765 \\
$64-65$ & & & 0.1613 & 0.1960 & 0.2343 & 0.2785 & 0.3222 & 0.3071 \\
\hline \hline
\end{tabular}

Table 12: England - Health employment covariance matrix for men, high-school dropouts, data vs model 


\begin{tabular}{lcccccccc}
\hline \hline \multirow{2}{*}{$\begin{array}{l}\text { Health by } \\
\text { age groups }\end{array}$} & \multicolumn{7}{c}{ Employment by age group } \\
\cline { 2 - 9 } & $50-51$ & $52-53$ & $54-55$ & $56-57$ & $58-59$ & $60-61$ & $62-63$ & $64-65$ \\
\hline \hline $50-51$ & 0.2202 & 0.1590 & 0.1475 & 0.1639 & 0.1538 & 0.1465 & 0.1069 & 0.0563 \\
$52-53$ & 0.2199 & 0.1810 & 0.1544 & 0.1562 & 0.1380 & 0.1214 & 0.1054 & 0.0654 \\
$54-55$ & 0.2589 & 0.1861 & 0.2217 & 0.1875 & 0.1629 & 0.1498 & 0.1260 & 0.0848 \\
$56-57$ & 0.2521 & 0.2133 & 0.2257 & 0.1993 & 0.1583 & 0.1388 & 0.1151 & 0.0773 \\
$58-59$ & 0.2588 & 0.2124 & 0.2122 & 0.2046 & 0.2064 & 0.1477 & 0.1259 & 0.0966 \\
$60-61$ & 0.2161 & 0.1832 & 0.1829 & 0.1882 & 0.1858 & 0.1882 & 0.1365 & 0.1064 \\
$62-63$ & 0.1438 & 0.1458 & 0.1390 & 0.1295 & 0.1382 & 0.1446 & 0.1166 & 0.0948 \\
$64-65$ & 0.1285 & 0.1179 & 0.1106 & 0.0893 & 0.1005 & 0.0915 & 0.1018 & 0.0961 \\
\hline & & & & & & & & \\
$50-51$ & 0.1812 & 0.1331 & 0.1462 & 0.1498 & 0.1527 & 0.1491 & 0.1355 & 0.1080 \\
$52-53$ & 0.1718 & 0.1743 & 0.1319 & 0.1461 & 0.1518 & 0.1530 & 0.1406 & 0.1122 \\
$54-55$ & 0.1528 & 0.1680 & 0.1733 & 0.1307 & 0.1448 & 0.1518 & 0.1452 & 0.1218 \\
$56-57$ & 0.1390 & 0.1501 & 0.1665 & 0.1718 & 0.1314 & 0.1484 & 0.1462 & 0.1262 \\
$58-59$ & 0.1212 & 0.1356 & 0.1493 & 0.1665 & 0.1763 & 0.1255 & 0.1401 & 0.1251 \\
$60-61$ & 0.1104 & 0.1191 & 0.1323 & 0.1481 & 0.1682 & 0.1764 & 0.1203 & 0.1204 \\
$62-63$ & 0.0990 & 0.1099 & 0.1212 & 0.1322 & 0.1495 & 0.1699 & 0.1708 & 0.0997 \\
$64-65$ & 0.0875 & 0.0971 & 0.1072 & 0.1188 & 0.1365 & 0.1547 & 0.1694 & 0.1546 \\
\hline \hline
\end{tabular}

Table 13: US - Health employment covariance matrix for men, high-school dropouts, data vs model

\subsubsection{Simulating health shocks}

To give a sense of the importance of the dynamic model, we compare the predicted employment decline from a one standard deviation negative shock to health as predicted by the estimated dynamic model relative to what would be predicted using OLS estimates of the effect of health on employment. Results are displayed in figures 5 and 6 . Our estimated dynamic model has a predicted employment response that is similar to the OLS estimates although the employment response is slightly longer lived. This is true for both England and the US. The reason why our estimates from the dynamic mode persist for longer is the strong correlation between lagged and current employment and also because lagged health appears to impact current employment, even after accounting for lagged employment and current health. However, the predictions from the OLS regression model combined with the dynamic model of health capture a very similar pattern. 

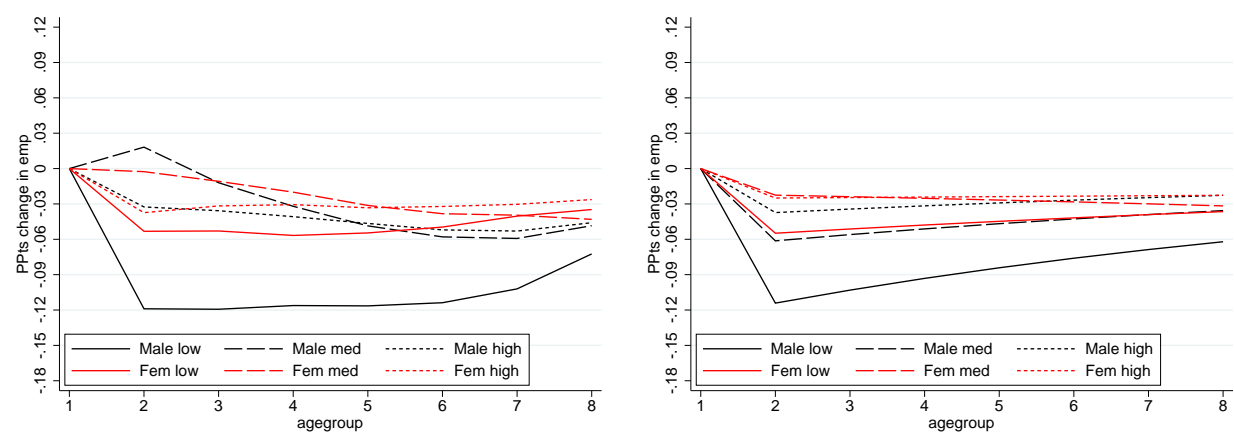

Figure 5: England - Model predictions (left) and OLS predictions (right) of employment response to a 1 standard deviation shock to the permanent component of health at age 50-51. Low, med and high are for high-school dropouts, high-school graduates and college graduates. Age groups 1 to 8 are for $50-51$ to $64-65$.
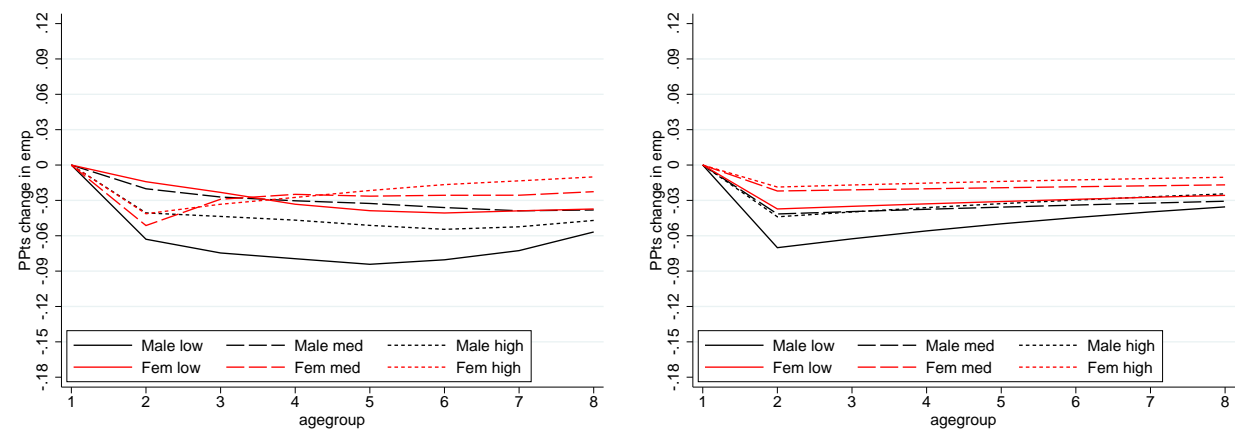

Figure 6: US - Model predictions (left) and OLS predictions (right) of employment response to a 1 standard deviation shock to the permanent component of health at age 50-51. Low, med and high are for high-school dropouts, high-school graduates and college graduates. Age groups 1 to 8 are for $50-51$ to $64-65$.

\section{Conclusions}

We estimate the effect of health on employment using a dynamic model. Our key findings are as follows:

1. The dynamic properties of health are well described by the sum of a highly persistent AR(1) component, plus a transitory component.

2. Transitory health shocks have little impact on employment.

3. Permanent health shocks have much bigger effects on employment.

4. Employment is highly persistent. Lagged employment strongly predicts current employment, even after accounting for the persistence in health. 


\section{References}

Blundell, R., J. Britton, M. C. Dias, and E. French (2016). Cognition, health, employment and wages near retirement in England. mimeo.

Blundell, R., E. French, and G. Tetlow (2016). Retirement incentives and labor supply. In J. Piggott and A. Woodland (Eds.), Handbook of the Economics of Population Aging. North Holland.

Bound, J. (1991). Self-reported versus objective measures of health in retirement models. Journal of Human Resources 26(1), 106-138.

Bound, J., M. Schoenbaum, T. R. Stinebrickner, and T. Waidmann (1999). The dynamic effects of health on the labor force transitions of older workers. Labour Economics 6(2), 179-202.

Bound, J., T. R. Stinebrickner, and T. A. Waidmann (2010). Health, economic resources and the work decisions of older men. Journal of Econometrics 156(1), 106-129.

Butler, J. S., R. V. Burkhauser, J. M. Mitchell, and T. P. Pincus (1987). Measurement error in self-reported health variables. Review of Economics and Statistics 69(4), 644-650.

Casanova, M. (2013). Revisiting the hump-shaped wage profile. Mimeo, UCLA.

Disney, R., C. Emmerson, and M. Wakefield (2006). Ill health and retirement in Britain: A panel data-based analysis. Journal of Health Economics 24(4), 621-649.

Kapteyn, A., J. P. Smith, and A. van Soest (2007). Vignettes and self-reports of work disability in the united states and the netherlands. American Economic Review 97(1), 461-473.

McFadden, D. (1989). A method of simulated moments for estimation of discrete response models without numerical integration. Econometrica: Journal of the Econometric Society, 995-1026.

Pakes, A. and D. Pollard (1989). Simulation and the aysmptotics of optimization estimators. Econometrica 57(5), 1027-1057.

Stern, S. (1989). Measuring the effect of disability on labor force participation. Journal of Human Resources 24(3), 361-395.

\section{Appendix A: Using Principal Components Analysis to construct the health index}

In this appendix we describe our Principal Components Analysis approach.

We are concerned that a health measure we look at to investigate the effect on employment and earnings will be subject to both measurement error - individuals may just be having a bad day, for example - and justification bias, where individuals report ill health as a consequence of having lower earnings or being unemployed. We attempt to deal with these problems by creating a health measure using a two-stage process. First, we attempt to deal with measurement error by taking a weighted average of the three subjective health measures, with the weights determined using principle components analysis. Second, to deal with justification bias, we regress this on all of the objective health measures, age, age squared, and a set of wave dummies (separately 
by gender and education) and use the estimated coefficients of the model to predict subjective health.

Specifically we take the first principal component of the data matrix of the three health subjective health measures, which we define as $H_{i, t, 1}^{S}, H_{i, t, 2}^{S}, H_{i, t, 3}^{S}$, which will give us weights $\hat{\psi}_{1}, \hat{\psi}_{2}, \hat{\psi}_{3}$, to construct the subjective health index

$$
\tilde{H}_{i, t}=\hat{\psi}_{1} H_{i, t, 1}^{S}+\hat{\psi}_{2} H_{i, t, 2}^{S}+\hat{\psi}_{3} H_{i, t, 3}^{S}
$$

We then take this index and estimate

$$
\tilde{H}_{i, t}=\alpha+X_{i, t}^{\prime} \delta+\sum_{k=1}^{7} \rho_{k} H_{i, t, k}^{O}+\epsilon_{i, t}
$$

where $X$ is vector including an age polynomial and a full set of wave dummies, and $H_{i, t, 1}^{O} \ldots H_{i, t, 7}^{O}$ are the objective health measures. Our measure of health that we use throughout the paper is then given by equation 9

$$
H_{i, t}=\hat{\alpha}+X_{i, t}^{\prime} \hat{\delta}+\sum_{k=1}^{7} \hat{\rho}_{k} H_{i, t, k}^{O}
$$

\section{Appendix B: Identification}

In this appendix we discuss the identification of the parameters driving health and employment.

\section{Identifying the parameters of the health process}

The structure of the health residual is simply identified from the auto-correlation moments in health, conditional on a polynomial in age. The health of process is described in equations (1) and (2) in the main text, which we reproduce here for convenience

$$
\begin{aligned}
h_{i a} & =\beta_{0}+x_{i a} \beta_{x}+\pi_{i a}+\epsilon_{i a} \\
\pi_{i a} & =\rho \pi_{i a-1}+\omega_{i a}
\end{aligned}
$$

where the indexes $i$ and $a$ stand for individual and age, $h$ is health measured as described in Section 3 and appendix A, $x$ is a polynomial in age, $\pi$ is the persistent health shock, assumed to follow an $\operatorname{AR}(1)$ process with innovation $\omega$ and $\epsilon$ is the transitory health shock. We assume that $(\omega, \epsilon)$ are iid and and mutually independent. All equations are education and gender specific and we omit dependence on these characteristics for simplicity.

We start by regressing $h$ on $x$ simply by OLS and predict the residuals from this regression, which we denote by $\hat{R}_{i a}$. Then

$$
\hat{R}_{i a}=\hat{\pi}_{i a}+\hat{\epsilon}_{i a}
$$

To identify the parameters characterizing the residual process we use the autocovariance mo- 
ments for the residual $R=\pi+\epsilon$ :

$$
\begin{aligned}
\operatorname{Var}\left(R_{i 0}\right) & =\sigma_{\pi 0}^{2}+\sigma_{\psi}^{2} \\
\operatorname{Var}\left(R_{i a}\right) & =\rho^{2 a} \sigma_{\pi 0}^{2}+\frac{1-\rho^{2 a}}{1-\rho^{2}} \sigma_{\omega}^{2}+\sigma_{\psi}^{2} \text { for } a=1, \ldots \\
E\left(R_{i a} R_{i a-1}\right) & =E\left(\rho \pi_{i a-1}+\omega_{i a}+\psi_{i a}\right)\left(\pi_{i a-1}+\psi_{i a-1}\right) \\
& =\rho\left(\rho^{2(a-1)} \sigma_{\pi 0}^{2}+\frac{1-\rho^{2(a-1)}}{1-\rho^{2}} \sigma_{\omega}^{2}\right)
\end{aligned}
$$

and in general, for $l>1$

$$
\begin{aligned}
E\left(R_{i a} R_{i a-l}\right) & =E\left(\pi_{i a}+\psi_{i a}\right)\left(\pi_{i a-l}+\psi_{i a-l}\right) \\
& =\rho^{l} \sigma_{\pi a-l}^{2} \\
& =\rho^{l}\left(\rho^{2(a-l)} \sigma_{\pi 0}^{2}+\frac{1-\rho^{2(a-l)}}{1-\rho^{2}} \sigma_{\omega}^{2}\right)
\end{aligned}
$$

From these expressions it is clear that identification of $\left(\sigma_{\pi 0}, \rho, \sigma_{\omega}, \sigma_{\psi}\right)$ requires at least 3 periods. Taking periods $a=0,1,2$, it is easy to show:

$$
\begin{aligned}
\rho & =\frac{E\left(R_{i 2} R_{i 0}\right)}{E\left(R_{i 1} R_{i 0}\right)} \\
\sigma_{\pi 0}^{2} & =\frac{E\left(R_{i 1} R_{i 0}\right)^{2}}{E\left(R_{i 2} R_{i 0}\right)} \\
\sigma_{\omega}^{2} & =\frac{E\left(R_{i 1} R_{i 0}\right)^{2}-E\left(R_{i 2} R_{i 0}\right)^{2}}{E\left(R_{i 2} R_{i 0}\right)}+\operatorname{Var}\left(R_{i 1}\right)-\operatorname{Var}\left(R_{i 0}\right) \\
\sigma_{\psi}^{2} & =\operatorname{Var}\left(R_{i 0}\right)-\frac{E\left(R_{i 1} R_{i 0}\right)^{2}}{E\left(R_{i 2} R_{i 0}\right)}
\end{aligned}
$$

\section{Identifying the parameters of the employment process}

The employment process is formalised in equations (4) and (5), which we reproduce here for convenience:

$$
\begin{aligned}
& E_{i a}^{*}=\alpha_{0}+\alpha_{E 1} E_{i a-1}+\alpha_{E 2}\left(E_{i a-1} * a\right)+x_{i a} \alpha_{x}+\delta_{0} \pi_{i a}+\delta_{1} \pi_{i a-1}+\gamma_{0} \epsilon_{i a}+\gamma_{1} \epsilon_{i a-1}+u_{i a} \\
& E_{i a}=\mathbf{1}\left(E_{i a}^{*}>0\right)
\end{aligned}
$$

where employment $E$ is a discrete variable with latent process $E^{*}$. The latter is a function of observed variables $x$, which include an cubic polynomial in age, health residuals $(\pi, \epsilon)$ and employment residual $u$. All equations are education and gender specific and we omit dependence on these characteristics for simplicity.

We assume all health and employment residuals are normally distributed and independent. Hence, the employment regression is a probit. Lagged employment is endogenous in this regression given its mechanical relationship with health residuals. We explicitly take this into account by simulating the employment and health residual processes jointly - thus formally accounting for the 
links between the two processes - and then matching conditional (on observed $x$ 's) employment rates, employment rates conditional on past employment and the current and lagged correlations between employment and health calculated on the model simulations with their data counterparts. Furthermore, endogeneity of initial employment is dealt with by starting the simulations 2 years prior to the start of the age interval we are considering. After this "burn in" phase, the structure of the relationship between employment and the health residual will have created the correlation between lagged employment and the overall residual in the employment equation that is consistent with the data moments.

Demonstrating identification in a linear probability model based on the set of moments we use is similar (although more laborious and tedious) to what we have done above for the health residuals. Suppose we know $\left(\alpha_{0}, \alpha_{x}, \alpha_{E 1}, \alpha_{E 2}\right)$. We can then predict the employment residuals $\left(\delta_{0} \pi_{i a}+\delta_{1} \pi_{i a-1}+\gamma_{0} \epsilon_{i a}+\gamma_{1} \epsilon_{i a-1}+u_{i a}\right)$ and use these to calculate their autocovariances and correlations with health residuals (current and lagged). Since we know all parameters in the health process, this procedure identifies $\left(\delta_{0}, \delta_{1}, \gamma_{0}, \gamma_{1}\right) .{ }^{14}$ The parameters $\left(\alpha_{0}, \alpha_{x}, \alpha_{E 1}, \alpha_{E 2}\right)$ can be identified from the employment rates and the correlations between employment, lagged employment and $x$. Estimating $\left(\alpha_{0}, \alpha_{x}, \alpha_{E 1}, \alpha_{E 2}, \delta_{0}, \delta_{1}, \gamma_{0}, \gamma_{1}\right)$ together ensures that the mechanical endogeneity of lagged employment is fully accounted for and the estimates are consistent. Finally, since imposing normality does not affect identification, a similar procedure can be used to identify the parameters in our non-linear model.

\footnotetext{
${ }^{14}$ Calculations are available from the authors upon request.
} 